\title{
Combination of Aerobic Exercise and Continuous Environmental Enrichment Improves Adult Male Rats' Spatial Memory: Study on Hippocampal Insulin Like Growth Factor 1 (IGF-1) and Fibroblast Growth Factor 2 (FGF-2) Expression
}

\author{
Sophie Yolanda ${ }^{1, *}$, Sri Redjeki ${ }^{1}$, Trinovita Andraini ${ }^{1}$, Dewi Irawati Soeria Santoso ${ }^{1}$, \\ Nurhadi Ibrahim ${ }^{1}$, Rena Mailani ${ }^{2}$ \\ ${ }^{1}$ Department of Medical Physiology, Faculty of Medicine, Universitas Indonesia, Jakarta, Indonesia \\ ${ }^{2}$ Graduate Program of Biomedical Sciences, Department of Medical Physiology, Faculty of Medicine, Universitas Indonesia, Jakarta, Indonesia \\ *Corresponding author. E-mail: sophie.y@ui.ac.id
}

Received date: Jan 30, 2019; Revised date: May 13, 2019; Accepted date: May 21, 2019

\section{Abstract}

B ACKGROUND: Memory declines with the progression of age through the neurodegeneration process. Aerobic exercise and environmental enrichment can delay neurodegeneration by improving neuroplasticity via expression of insulin like growth factor 1 (IGF-1), fibroblast growth factor 2 (FGF-2) and other proteins. Combination treatment of aerobic exercise and continuous environmental enrichment and their effect on the expression of IGF-1 and FGF-2 which were expected to improve memory function has not been studied previously. Thus, this study aimed to observe it.

METHODS: This is an experimental research using 24 male Wistar rats (Rattus norvegicus, 300-400 g, age 7-8 months) divided randomly into 4 groups: control (C), aerobic exercise (A), continuous (EE), and combination of aerobic exercise and continuous environmental enrichment (A-EE). At the end of an 8-week treatment, rats were sacrificed, and an enzyme-linked immunosorbent assay
(ELISA) examination was performed to assess hippocampal IGF-1 and FGF-2 levels.

RESULTS: In the $8^{\text {th }}$ week, A-EE group showed the best improvement in rats' spatial memory $(47.84 \pm 10.6 \%)$ followed by EE group $(45.03 \pm 4.1 \%$ ), A group (38.61 \pm 3.8 $\%$ ), and $\mathrm{C}$ group (22.76 $\pm 7.12 \%)$. However, A-EE group's hippocampal IGF-1 (16.21 $\pm .56 \mathrm{ng} / \mathrm{mg}$ protein) and FGF-2 $(1.29 \pm 0.57 \mathrm{ng} / \mathrm{mg}$ protein) expression were not higher than other groups.

CONCLUSION: Improvement in memory function in the combination group is a result of induction of various growth factors' expression in the hippocampus, including IGF-1 and FGF-2, but the primary pathway of memory function improvement may be from other growth factors.

KEYWORDS: spatial memory, aerobic exercise, environmental enrichment, hippocampus, IGF-1, FGF-2

Indones Biomed J. 2019; 11(2): 210-6

\section{Introduction}

Learning and memory play an important role in everyday life and are essential to the survival of people and animals. (1) Memory declines with progression of age through the neurodegeneration process. External stimuli such as aerobic exercise and environmental enrichment can delay this neurodegeneration process. It has been shown that aerobic exercise increases memory and learning in young adult rats through improving plasticity, synaptic protein and neurotrophic factors in the brain. $(2,3)$ Previous study showed that young adult rats given aerobic exercise with light intensity and long duration has better spatial memory function than rats given aerobic exercise with light intensity and short duration, or high intensity and short duration, and high intensity and long duration.(4) Environmental enrichment consists of sensory, motoric, social, and 
cognitive stimuli that will improve memory function. (5) Continuous environmental enrichment can enhance spatial memory function through increased expression of postsynaptic density 95 (PSD-95) and neuroligin.(6)

Aerobic exercise and environmental enrichment improve neuroplasticity via expression of various synaptic proteins and growth factors, some of them are insulin like growth factor 1 (IGF-1) and fibroblast growth factor 2 (FGF2). IGF-1 as a trophic factor is important for growth and metabolic reactions. The main sources of IGF-1 production are liver dependent growth hormone action, and local production in muscle, adipose tissue, gut, cartilage, bone, and including brain.(7) Lately IGF-1's role as a key growth factor in the nervous system, which includes modulation of synaptic plasticity, synaptic density, neural transmission, and adult neurogenesis is emerging.(8)

FGF-2 is an essential growth factor in central nervous system (CNS) development and even in adult neurogenesis. (9) FGF-2 expression in neurogenic niches, subventricular zone (SVZ), hippocampal subgranular zone (SGZ), and its role in regulating neural stem cells and progenitor cells implicates its role in adult neurogenesis.(10) In synaptic plasticity, FGF-2 has been shown in its modulation and FGF-2 also affects axonal branching both in vivo and in vitro. Application of FGF-2 enhanced long term potentiation (LTP) in rat hippocampal slices, and intracerebroventricular (ICV) administration of FGF-2 and epidermal growth factor (EGF) to anesthetized rats increases generation of long term potentiation in the synapses between the perforant path and the dentate gyrus cells.(9)

Combination treatment of aerobic exercise and continuous environmental enrichment and their effect on the expression of hippocampal IGF-1 and FGF-2 which were expected to improve memory function has not been studied previously. Thus, this study aims to assess the effect of combination treatment of aerobic exercise and continuous environmental enrichment on spatial memory function, hippocampal IGF-1 and FGF-2.

\section{Methods}

\section{Animals and Housing}

The use of animals in this work was approved by the Health Research Ethics Committee, Faculty of Medicine, Universitas Indonesia (No. 1018/UN2.F1/ETIK/2017). Male Wistar rats were obtained from health research and development's animal laboratories at 7 months of age, weighing 300-400 grams, the normal body weight for male
Wistar rats at that age.(10) Animals were given access to food and water ad libitum. Animals were maintained on a 12-hour light/dark cycle in a controlled temperature and humidity. Acclimatization period was performed prior to treatment for two weeks to introduce the animals to Y-maze, the environmental enrichment cage, treadmill and other research conditions.

A symmetrical Y-maze was used to conduct spontaneous alternation test. The test was comprised of one five-minute trial, wherein the rat was allowed to explore all three arms of the Y-maze.(11) In the event of a rat climbing above the maze walls, the rat would be returned immediately to the corresponding arm. To avoid placement bias, the start arm of each test between animals was varied. Before and after memory test, Y-maze was cleaned with antiseptic liquid and alcohol, waited until dry to ensure no more smell lingered on the maze before the next test, this is preformed to avoid bias.(12) The definition of spontaneous alternation (\%) was consecutive entries in 3 different arms (ABC) divided by the number of possible alternations (total arm entries minus 2).(11) At the beginning of the study, memory test was performed prior to treatment to obtain rats' baseline memory function. Rats that entered less than eight arms during the five-minute trial were excluded from the analysis. Memory test was performed every 2 weeks ( $2^{\text {nd }}, 4^{\text {th }}, 6^{\text {th }}$ and $8^{\text {th }}$ week $)$.

After obtaining the rats' baseline memory function, the twenty-four adult male Wistar rats were divided randomly into four groups: control group (C), aerobic exercise group (A), environmental enrichment group (EE), and combination of aerobic exercise and environmental enrichment (AEE) group. All animals except the groups exposed to environmental enrichment were housed in standard cages. The groups treated with environmental enrichment were placed in environmental enrichment cage (Marlau's cage) continuously for 24 hours. All animals exposed to exercise were removed from their cages during exercise treatment. Figure 1 showed the illustration of Marlau's cage and Maze configuration.

\section{Aerobic Exercise}

Exercise was performed on a four-track animal treadmill. Exercise was given to relevant groups for 5 days/week (Monday to Friday) for 8 weeks. The exercise performed was aerobic exercise $(20 \mathrm{~m} / \mathrm{min}$ treadmill speed $)$ with a duration of 30 minutes.(4) The speed for warming up and cooling down was $10 \mathrm{~m} / \mathrm{min}$ with a duration of 5 minutes each. This protocol referred to a previous study protocol (4), with treadmill speed of $20 \mathrm{~m} / \mathrm{min}$ for 30 minutes. Previous 

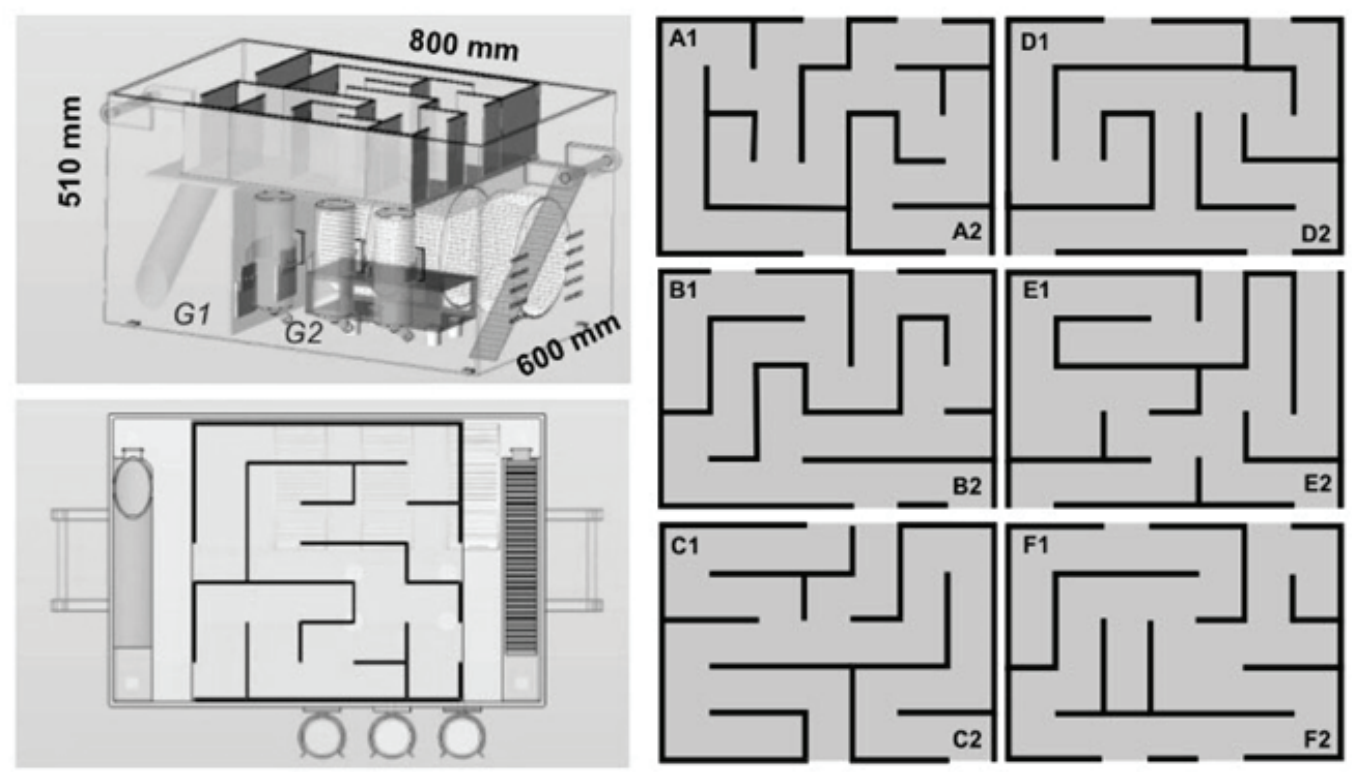

Figure 1. Marlau's cage and the maze configuration.(6)

study has shown that aerobic exercise with light intensity and long duration $(20 \mathrm{~m} / \mathrm{min}$ for 30 minutes) were the best combination in improving rats' spatial memory. To confirm that the exercise given was indeed aerobic, a pilot study was conducted using six rats to examine the rats' plasma lactate immediately at the end of one exercise session. The lactate test results from all six mice showed lactate plasma levels below 4 , confirming that the exercise was indeed aerobic and can be adapted for this study. Another study also observed that lactate threshold was reached at a treadmill speed of $26.21 \mathrm{~m} / \mathrm{min}$.(13) This showed that the exercise given at treadmill speed lower than the speed of lactate threshold was indeed aerobic exercise.

\section{Environmental Enrichment}

EE groups was given by housing animals on a larger cage (cage size: $800 \times 600 \times 510 \mathrm{~mm}$ consisting of two floors) containing many different objects besides food and water, including running wheels, a tunnel, stairs, maze, and many other colorful objects. EE and A-EE groups were put inside the EE cage continuously for 24 hours a day, 7 days a week, for 8 weeks except during exercise.(14) To feed themselves, rats had to climb from the lower floor to the top floor, go through a maze and then go down through the sliding tunnel. Physical activity was encouraged by the large exploration area and free access to running wheels. Cognitive stimulation is obtained by changing the maze configuration 3 times a week on every Monday, Wednesday and Friday using 6 mazes (A-F) consisting of a total of twelve maze configurations (A1-F1 and A2-F2).(14)

\section{Spontaneous Alternation Test Y-Maze}

A symmetrical Y-maze was used to conduct spontaneous alternation test. The test was comprised of one five-minute trial, where in the rat was allowed to explore all three arms of the Y-maze.(11) In the event of a rat climbing above the maze walls, the rat would be returned immediately to the corresponding arm. To avoid placement bias, the start arm of each test between animals was varied. The definition of spontaneous alternation (\%) was consecutive entries in 3 different arms (ABC) divided by the number of possible alternations (total arm entries minus 20).(12) On the beginning of the study, rats that entered less than eight arms during the five-minute trial were excluded from the analysis. Memory test was performed every 2 weeks $\left(2^{\text {nd }}\right.$, $4^{\text {th }}, 6^{\text {th }}$ and $8^{\text {th }}$ week).

\section{IGF-1 and FGF-2 Levels Measurement}

At the end of week 8, rats were sacrificed with cervical dislocation. This method was chosen to prevent ischemia to the brain. The brain was collected after cervical dislocation by using micropunch dissection on frozen slices to isolate the hippocampus, then homogenization was performed on the hippocampal tissue. Hippocampal tissue weight was measured and the smallest size from all samples were taken. The tissue was then homogenized with saline buffer and centrifuged for 10 minutes at the speed of $3000 \mathrm{rpm}$ for the supernatant.

Bradford test was performed to measure total protein in hippocampus. The enzyme-linked immunosorbent assay (ELISA) examination was performed to assess hippocampal 
IGF-1 and FGF-2 levels. The ELISA technique used was the sandwich technique to detect the antigen-antibody reaction of IGF-1 and FGF-2. The ELISA kit used was Qayeebio ELISA kit (Catalogue \#QY-E10935, Qayee-Bio for Life Science, Shanghai, China).

\section{Statistical Analysis}

The Shapiro-Wilk test was used to verify data normality. Repeated two-way ANOVA was used to analyzed memory function between weeks and groups. One-way ANOVA was used to analyzed body weight, hippocampal IGF-1 and FGF-2 levels followed by Least Significant Difference (LSD) post hoc.

\section{Results}

\section{Body Weight}

Weight measurement is carried out at the beginning of the study, $2^{\text {nd }}$ week, $4^{\text {th }}$ week, $6^{\text {th }}$ week and end of the treatment period. The mean weight of each group can be seen in Figure 2. Figure 2 shows decreased body weight of all animals with treatment except in control group. The results of statistical analyses showed that there were significant differences in body weight between at week 6 between group $\mathrm{C}$ with group $\mathrm{A}(p=0.00)$, between group $\mathrm{C}$ with group $\mathrm{EE}(p=0.00)$, and between group $\mathrm{C}$ with group A-EE $(p=0.01)$. There were also significant differences in body weight at week 8 between group $\mathrm{C}$ with group $\mathrm{A}$ $(p=0.00)$, between group $\mathrm{C}$ with group $\mathrm{EE}(p=0.00)$, and between group $\mathrm{C}$ with group A-EE $(p=0.00)$.

\section{Memory Function}

Our study showed that starting from the $6^{\text {th }}$ week, groups with treatment (A, EE and A-EE groups) showed significantly higher memory function compared to control group. At the last week, A-EE group have the highest memory score $(47.84 \pm 10.6 \%)$, followed by EE group $(45.03 \pm 4.1 \%)$ and A group $(38.61 \pm 3.8 \%$ ), while the control group has the lowest memory score $(22.76 \pm 7.12 \%$ ) (Figure 3 ).

\section{Hippocampal IGF-1 Levels}

Our study showed that the control group hippocampal IGF-1 levels $(29.9 \pm 6.44 \mathrm{ng} / \mathrm{mg}$ protein) was the highest, followed by EE group $(22.49 \pm 12.76 \mathrm{ng} / \mathrm{mg}$ protein), A group $(16.81 \pm 2.57 \mathrm{ng} / \mathrm{mg}$ protein), and A-EE group (16.21 \pm 7.56 $\mathrm{ng} / \mathrm{mg}$ protein) (Figure 4). Based on statistical test, there were significant differences between control group with group A ( $p=0.014)$ and between control group with group A-EE $(p=0.004)$.

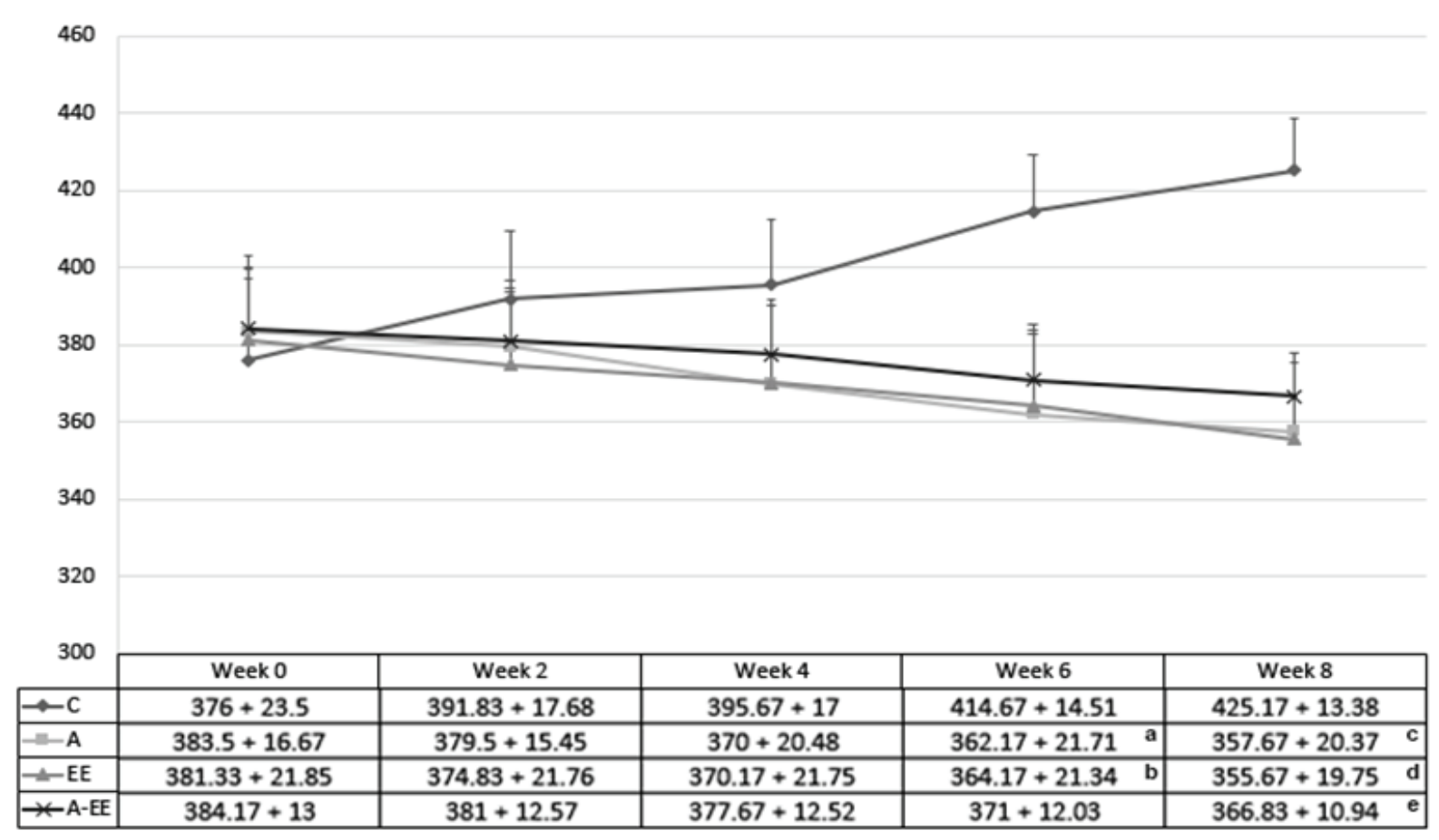

Figure 2. Body weight between groups and weeks. Data are shown in mean values, error bars indicate standard deviation. C: control; A: aerobic; EE: environmental enrichment; A-EE: combination of aerobic and environmental enrichment. ${ }^{\mathrm{a}} p=0.00 v s$. C week 6 ; ${ }^{\mathrm{b}} p=0.01$ vs. C week $6 ;{ }^{\mathrm{c}} p=0.00 v s$. C week $8 ;{ }^{\mathrm{d}} p=0.00 v s$. C week $8,{ }^{\mathrm{e}} p=0.001 v s$. C week 8 . Tested with repeated two-way ANOVA. 


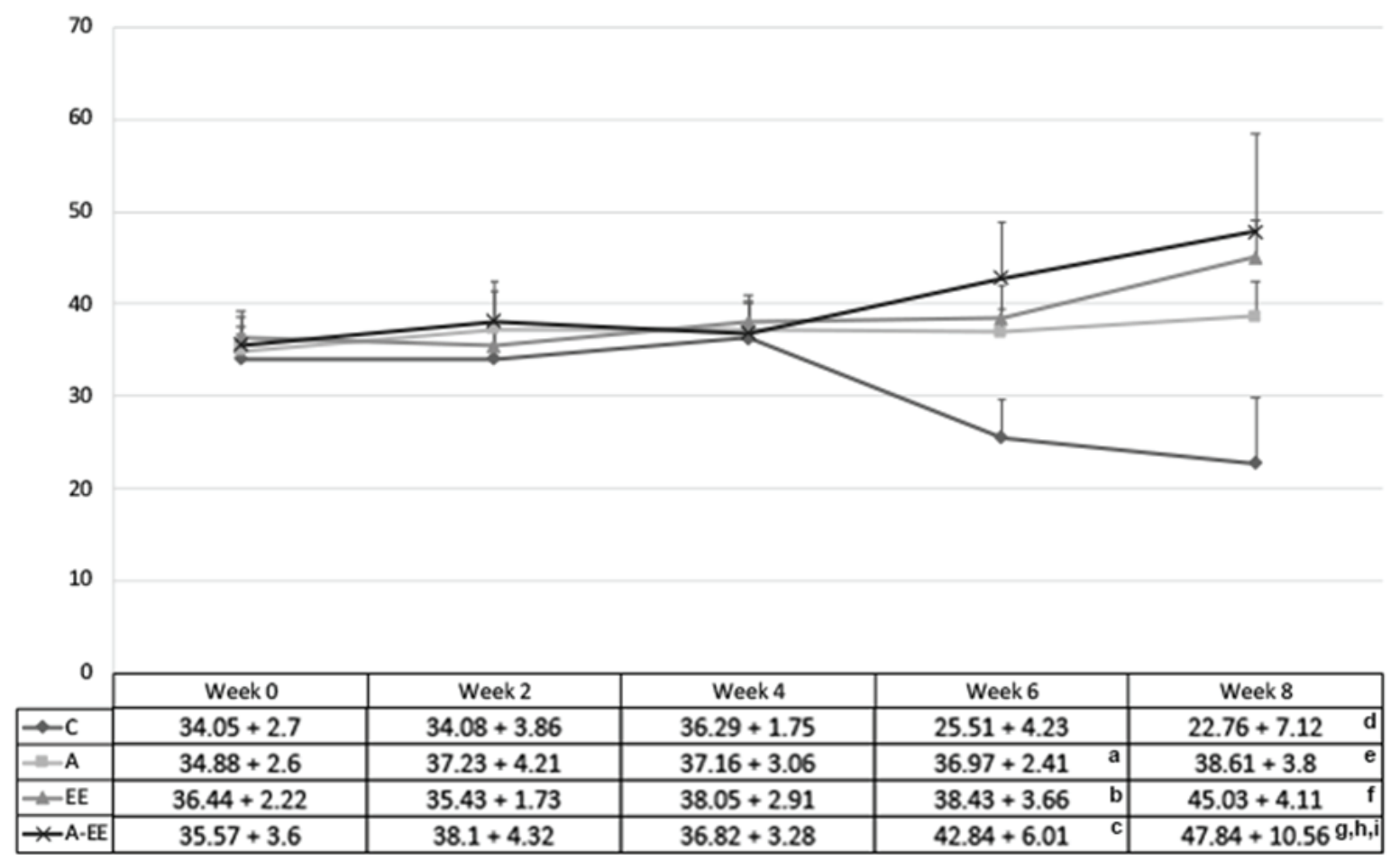

Figure 3. Spontaneous alternation test between group and weeks. Data are shown in mean values, error bars indicate standard deviation. C: control; A: aerobic; EE: environmental enrichment; A-EE: combination of aerobic and environmental enrichment. ${ }^{\mathrm{a}} p=0.003 \mathrm{vs}$. C week $6 ;{ }^{\mathrm{b}} p=0.0003 v s$. C week $6 ;{ }^{\mathrm{c}} p=0.0001 v s$. C week $6 ;{ }^{\mathrm{d}} p=0.0001 v s$. C week 8 ; ${ }^{\mathrm{e}} p=0.0001 v s$. C week $8 ;{ }^{\mathrm{f}} p=0.0001 v s$. C week $8 ;{ }^{\mathrm{g}} p=0.05 v s$. A week $8 ;{ }^{\mathrm{h}} p=0.003 v s$. C week $0 ;{ }^{i} p=0.0008 v s$. A-EE week 0 . Tested with repeated two-way ANOVA.

\section{Hippocampal FGF-2 Levels}

Our study showed that the highest level of hippocampal FGF-2 was found in EE group (1.92 $\pm 0.97 \mathrm{ng} / \mathrm{mg}$ protein), followed by A group $(1.32 \pm 0.36 \mathrm{ng} / \mathrm{mg}$ protein), A-EE group $(1.29 \pm 0.57 \mathrm{ng} / \mathrm{mg}$ protein), and control group $(0.18 \pm 0.07 \mathrm{ng} / \mathrm{mg}$ protein) (Figure 5). Based on statistical test, there were significant differences between A with control group $(p=0.00)$, between EE with control group $(p=0.00)$, and between A-EE with control group $(p=0.00)$.

\section{Discussion}

Aerobic physical exercise protocol used in this study referred to a previous study protocol (4), with treadmill speed of $20 \mathrm{~m} / \mathrm{min}$ for 30 minutes. Prior to the aerobic treatment, a pilot study was conducted using six rats to examine the rats' plasma lactate immediately at the end of one exercise session. The lactate test results from all six mice showed

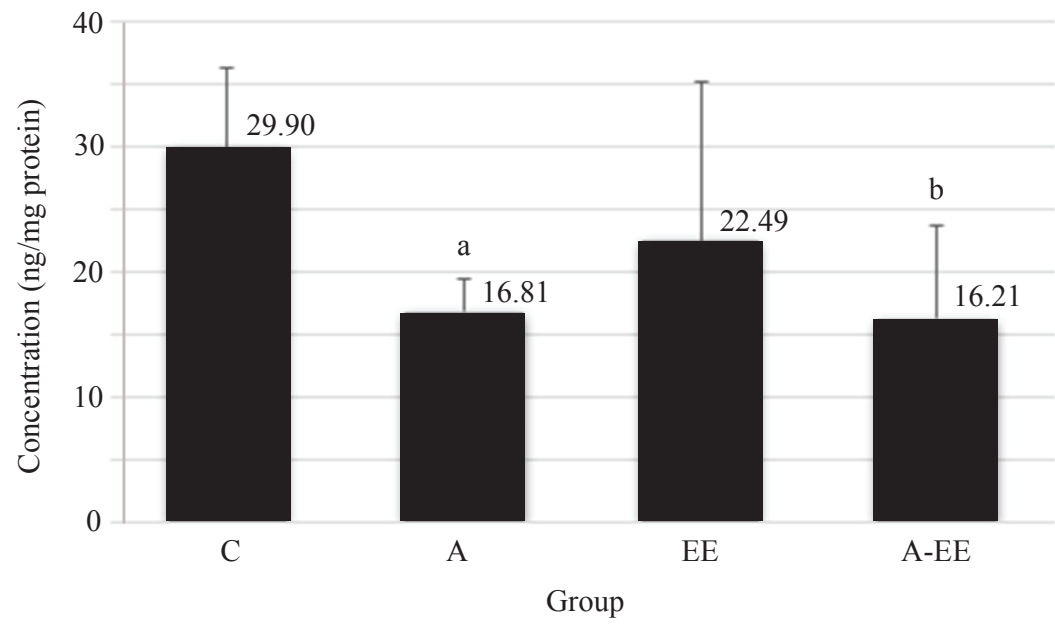

Figure 4. Hippocampal IGF-1 levels. Data are shown in mean values, error bars indicate standard deviation. C: control; A: aerobic; EE: environmental enrichment; A-EE: combination of aerobic and environmental enrichment. ${ }^{\mathrm{a}} \mathrm{p}=0.014$ vs. $\mathrm{C} ;{ }^{\mathrm{b}} p=0.004$ vs. C. Tested with one-way ANOVA. 


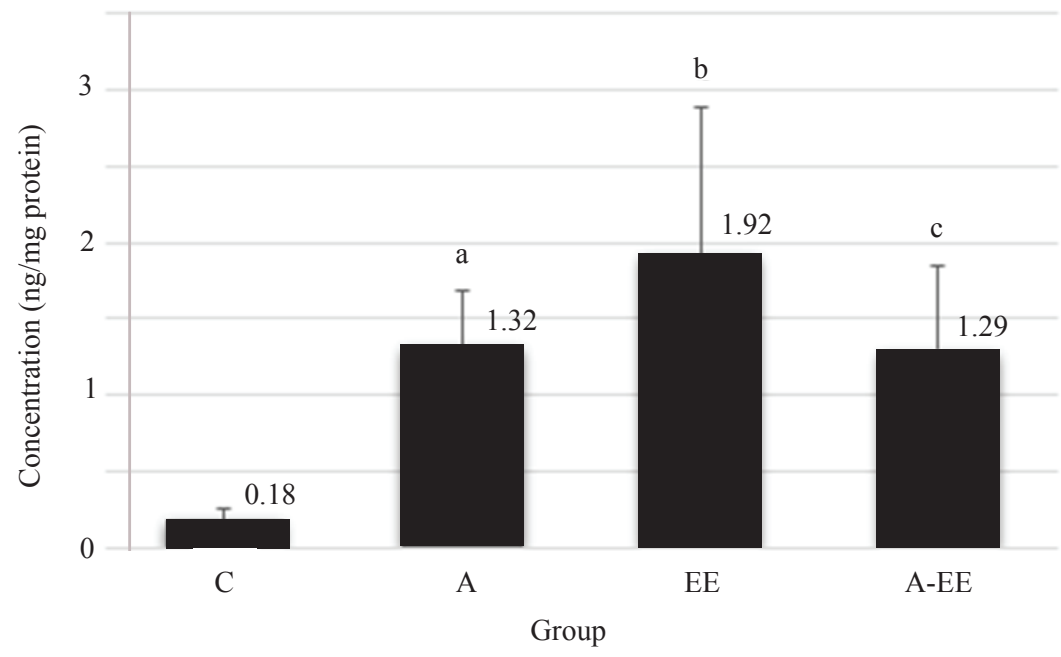

Figure 5. Hippocampal FGF-2 levels. Data are shown in mean values, error bars indicate standard deviation. C: control; A: aerobic; EE: environmental enrichment; A-EE: combination of aerobic and environmental enrichment. ${ }^{\mathrm{a}} p=0.00 v s . \mathrm{C} ;{ }^{\mathrm{b}} p=0.00 v s . \mathrm{C} ;{ }^{\mathrm{c}} p=0.00$ vs. C. Tested with one-way ANOVA lactate plasma levels below 4 . This means that the exercise given was indeed aerobic and can be adapted for this study.

Environmental enrichment was given by placing rats in the Marlau's cage for 24 hours non-stop. Previous study has shown that a 24-hour environmental enrichment exposure has better impact on memory function than 3 hours per day due to increased nerve activity in continuous stimulus.(6)

In our study, rats treated with combination of aerobic exercise and continuous environmental enrichment showed the highest spontaneous alternation test Y-maze. This showed better spatial memory in rats. In line with this, a previous study reported that combination of aerobic exercise and continuous environmental enrichment showed the highest improvement in spatial memory, by increasing synaptic proteins such as PSD-95 and neuroligin.(6) These synaptic proteins are regulated by various growth factors, some of which are IGF-1 and FGF-2.

IGF-1 production is regulated through growth hormone/growth hormone receptor/janus kinase 2/signal transducer and activator of transcription 5 (GH/GHR/JAK2/ STAT5) signaling cascade. IGF-1 level changes during the day, suggesting some circadian control. The circadian clock generates rhythms in physiology and behavior known as circadian rhythm and synchronizes the processes in organisms with the environment.(15) Cryptochrome (CRYs) is an essential player in regulation of IGF-1 production and signaling, and CRYs is essential for circadian clock function.(15) Liver synthesis of IGF-1 is a process regulated by growth hormone. Factors that affect growth hormone production in the body includes going to sleep, deep sleep or slow wave sleep (SWS), exercising, eating, aging process, obesity, and fasting.(16)

In this study, group treated with combination of aerobic exercise and EE (A-EE) showed the lowest hippocampal
IGF-1 level. This may be explained by a limitation of the study. The treadmill room was located in a different room with the animal cage room, thus making it necessary to mobilize animals with aerobic exercise treatment. This may cause disturbances in the 12-hour light-dark cycle which can cause disruption of the animals' circadian rhythm. In accordance with this, a previous study regarding circadian rhythm (15) observed that in the liver and other tissues of mice lacking CRYs, the expression of IGF-1 was reduced on both the mRNA and protein levels, which was correlated with the reduced levels of circulating IGF-1 in these mice.

In addition, IGF-1 is also expressed by food stimulation. When food comes in contact with the gastrointestinal tract, IGF-1, whose signal pathway is similar to insulin, immediately performs anabolic process. The highest hippocampal IGF-1 levels in control group may be explained in part due to food metabolism process. Gastrointestinal tissue expresses IGF-1 for metabolism of glucose, carbohydrate and protein.(17) Besides that, adipose tissue also expresses IGF-1 for regulation of fat metabolism and to prevent weight gain. The control group, in which the body weight increases the highest due to lack of physical activity, may had increased fat accumulation in adipose tissue, thus may be expressing IGF-1 for fat metabolism.(18)

Improvement of spatial memory is not only induced by IGF-1 but also FGF-2. FGF-2 expression is also induced by external stimuli such as aerobic exercise and environmental enrichment. In vitro, FGF-2 was found to function to stimulate the proliferation of neural stem cells efficiently and also to induce adult stem cell proliferation by maintaining progenitor cells in the cell cycle and preventing it further differentiating. The importance of FGF-2 in the proliferation of neural stem cells in vivo has been shown. 
FGF-2 may also modulate the synapses' plasticity and axonal branching in hippocampal neurons in in vitro and in vivo studies. The FGF-2 application can increase LTP in mouse hippocampus, and injection of EGF and ICV FGF-2 promote LTP in synapses between perforated pathways and rat dentatus gene cells that have been anesthetized.(19)

Aerobic exercise induces the expression of FGF-2 to help the angiogenesis process of forming new blood vessels to improve the distribution of blood flow to the tissues that require it, including the brain (9), while environmental enrichment increases the expression of FGF-2 through neurogenesis. In the CNS, FGF-2 is widely distributed not only in neurons but also glial cells. Sensory and cognitive input on environmental enrichment stimulates a higher FGF-2 expression.(20) This is consistent with this study which shows that hippocampal FGF-2 concentrations are highest in the EE group compared to other groups.

The hippocampal total protein levels in group treated with A-EE combination was the highest compared to other groups. From this result, we may also assume that A-EE improves memory function through increased expression of other growth factors, such as brain-derived neurotropic factor (BDNF), or nerve growth factor (NGF).

\section{Conclusion}

Improvement of memory function in group treated with combination of aerobic exercise and environmental enrichment is a result of induction of various protein expression in the hippocampus, including IGF-1 and FGF2 , but these proteins may not be the primary players in improvement of memory function improvement.

\section{Acknowledgements}

This research is funded by Hibah Publikasi Terindeks Internasional Untuk Tugas Akhir Mahasiswa UI (PITTA) Universitas Indonesia 2018 No. 2132/UN2.R3.1/ HKP.05.00/2018.

\section{References}

1. Kandel ER, Schwartz JH, Jessell TM, Siegelbaum SA. Principles of Neural Science. 5th ed. Mack S, editor. New York: The McGrawHill Companies, Inc.; 2013.

2. Trejo JL, LLorens-Martín MV, Torres-Alemán I. The effects of exercise on spatial learning and anxiety-like behavior are mediated by an IGF-I-dependent mechanism related to hippocampal neurogenesis. Mol Cell Neurosci. 2008; 37: 402-11.

3. Cancela JM, Ayán C, Varela S, Seijo M. Effects of a long-term aerobic exercise intervention on institutionalized patients with dementia. J Sci Med Sport. 2016; 19: 293-8.

4. Kartinah NT, Abdullah F, Ayu AD, Bariroh T. Low-intensity exercise improves neuroplasticity and spatial memory on young adult of male wistar rats. J Exerc Physiol. 2018; 21: 19-28.

5. Alwis DS, Rajan R, Sachdev RNS. Environmental enrichment and the sensory brain : the role of enrichment in remediating brain injury. Front Syst Neurosci. 2014; 8: 156. doi: 10.3389/fnsys.2014.00156

6. Abdullah F. Peran latihan fisik aerobik, model environmental enrichment (EE) dan kombinasinya terhadap memori spasial tikus wistar jantan: kajian ekspresi protein neuroligin-1 dan PSD-95 [Thesis]. Jakarta: Universitas Indonesia; 2017.

7. Dyer AH, Vahdatpour C, Sanfeliu A, Tropea D. The role of insulinlike growth factor 1 (IGF-1) in brain development, maturation and neuroplasticity. Neuroscience. 2016; 325: 89-99.

8. Vicario-abejón C. IGF-I : a key growth factor that regulates neurogenesis and synaptogenesis from embryonic to adult stages of the brain. Front Neurosci. 2016; 10: 52. doi: 10.3389/ fnins.2016.00052.

9. Woodbury ME, Ikezu T. Fibroblast growth factor-2 signaling in neurogenesis and neurodegeneration. J Neuroimmune Pharmacol. 2014; 4: 92-101.

10. Yoon BH, Kim CJ, Romero R, Jun JK, Park KH, Choi ST, et al. The laboratory rat: relating its age with human's. Am J Obstet Gynecol. 2014; 4: 624-30.

11. Wolf A, Bauer B, Abner EL, Ashkenazy-frolinger T, Anika M. A comprehensive behavioral test battery to assess learning and memory in 129S6 / Tg2576 mice. PLoS One. 2016; 11: e0147733. doi: 10.1371/journal.pone.0147733.

12. Pioli EY, Gaskill BN, Gilmour G, Tricklebank MD, Dix SL, Bannerman $\mathrm{D}$, et al. An automated maze task for assessing hippocampus-sensitive memory in mice. Behav Brain Res. 2014; 261: 249-57.

13. Brito Vieira W, Halsberghe M, Schwantes M, Perez S, Baldissera $\mathrm{V}$, Prestes $\mathrm{J}$, et al. Increased lactate threshold after five weeks of treadmill aerobic training in rats. Brazilian J Biol. 2014; 74: 444-9.

14. Fares RP. Erythropoietin and Enriched Housing in Marlau ${ }^{\mathrm{TM}}$ Cages Protect Neurons and Cognitive Function in Epileptic Rats. Human Health and Pathology. Lyon: Université Claude Bernard; 2009.

15. Chaudhari A, Gupta R, Patel S, Velingkaar N, Kondratov R, Chernoff J. Cryptochromes regulate IGF-1 production and signaling through control of JAK2-dependent STAT5B phosphorylation. Mol Biol Cell. 2017; 28: 834-42.

16. Åberg ND, Lind J, Isgaard J, Kuhn HG. Peripheral growth hormone induces cell proliferation in the intact adult rat brain. Growth Horm IGF Res. 2017; 20: 264-9.

17. Bortvedt SF, Lund PK. Insulin-like growth factor 1: common mediator of multiple enterotrophic hormones and growth factors. Curr Opin Gastroenterol. 2012; 28: 89-98.

18. Boucher J, Softic S, Ouaamari A El, Krumpoch MT, Kleinridders A, Kulkarni RN, et al. Differential roles of insulin and IGF-1 receptors in adipose tissue development and function. Diabetes. 2016; 65: 2201-13.

19. Zechel S, Werner S, Unsicker K, Bohlen O Von. Expression and functions of fibroblast growth factor 2 (FGF-2) in hippocampal formation. Neuroscientist. 2010; 16: 357-73.

20. Seo JH, Yu JH, Suh H, Kim M, Cho S. Fibroblast growth factor-2 induced by enriched environment enhances angiogenesis and motor function in chronic hypoxic-ischemic brain injury. PLoS One. 2013;8: e74405. doi: 10.1371/journal.pone.0074405. 